Bartok Ruxandra ${ }^{1}$, Dimitriu B. ${ }^{1}$, Varlan C. ${ }^{1}$, Stanciu R. ${ }^{1}$, . Scarlatescu Sanziana ${ }^{1}$, Mitran Loredana ${ }^{2}$, Mitran M. ${ }^{3}$, Gheorghiu Irina ${ }^{1}$, Suciu Ioana ${ }^{1}$, Iliescu D.M. ${ }^{4}$

\title{
Microscopic evaluation regarding time behavior of orthodontic cements used for disjunctor cementing
}

"Faculty of Dental Medicine, UMF "Carol Davila" Bucharest

${ }^{2}$ Elias Hospital Bucharest

${ }^{3}$ Faculty of Medicine, UMF "Carol Davila" Bucharest

${ }^{4}$ Faculty of medicine, University „Ovidius” Constanta

\begin{abstract}
In order to fulfill their function, orthodontic devices must be cemented on teeth using orthodontic rings. The retention of the orthodontic ring is influenced mainly by the type of dental-ring adhesion. This study was initiated to determine possible microleakage events while using zinc phosphate cement Adhesor (Spofa Dental), conventional glass ionomer Ketac Cem (3M ESPE) and Fuji Ortho (GC) and a compomer Transbond Plus ( 3M Unitek). The results of the study are consistent with those reported in the literature reference, the compomer is the preferred adhesive material for cementing the orthodontic rings, compared to conventional glass ionomer cements and zinc-phosphate cement.
\end{abstract}

Keywords: orthodontic ring; cementation; microleakage; cracks

Gheorghiu Irina-Maria

Faculty of Dental Medicine, UMF "Carol Davila" Bucharest Bd. Libertatii 18, bloc 104, sc.2, ap 23, sector V, Bucuresti; email: igheorghiu@hotmail.com phone: +40744305591 ;

\section{Introduction}

The retention of the orthodontic ring may be mechanically affected because of the adaptation to the tooth side walls influenced by cement adhesion [1]. The various properties of the cements have been tested and developed in order to improve retention of orthodontic rings [2,3].

For the last two decades, glass ionomer cements have become a custom for cementing the orthodontic rings. They adhere to enamel and metal, releasing fluoride and thereby inhibit microbial activity [4]. Adding resins to formulate cement facilitated polymerization, thus enabling faster adhesion. There are many advantages of the polymerizable materials to conventional cements $[5,6,7]$. The variation in the chemical composition and the setting time of the combination of the ionomer to resin enhance a greater adhesion force than conventional ionomer doe $[8,9]$.

The aim of this study is to determine possible microleakage events while using zinc phosphate cement (Adhesor, Spofa Dental), conventional glass ionomer (Ketac Cem, 3M ESPE and Fuji Ortho, GC) 
and a compomer (Transbond Plus, 3M Unitek).

Adhesor (Spofa Dental) is a product well known for decades. It is a zinc-phosphate cement which has been widely use for temporary fillings, filling of root canals with gutta-percha post, cement lining under amalgam and composite fillings. It is use in prosthetics for luting metal and metal-ceramic crowns and bridges and also in orthodontics. It is affordable and easy to use and this "old- fashioned" cement reveals to certain extent better properties than some of the "up-to-date" ones: it shows outstanding mechanical properties and high compressive strength. However we have to mention its harmful potential to dental pulp as a result of residual acidity.

Fuji Ortho (GC) is a self-cured, resin reinforced glass ionomer (RMGIC) ideally suited for bonding cement to orthodontic brackets and bands. This resin modified glass ionomer cement (RMGIC) has a good bonding strenght and its placement in a wet field simplifies application and bonding procedures [10]. It can be used with a non-etch or etch technique. Fuji Ortho (GC) presents significant long-term fluoride release and recharge, excellent adhesion, removal of orthodontic appliances easy but with no enamel fractures or decalcification. The product is easy to use and proved a high rate of clinical success.

Transbond Plus (3M Unitek) is a polyacidmodified resin composite (compomer) used for orthodontic purposes. This light-curing compomer combine certain features of the traditional dental composite resin and glass ionomer cements: good fluoride release and low microleakage [11]. The compomer cements has typically useful for shortterm orthodontic banding.

Ketac Cem (3M ESPE) is a permanent luting glass ionomer cement which has been in clinical use for almost 30 years. It is a product with high level of successful biocompatibility, excellent sealing and marginal adhesion and very good dimensional stability $[12,13,14]$. It is a simple and user-friendly cementation material. Proven long- term clinical success makes it ideal for: cementation of inlays, onlays, crowns, and bridges made from metal or metal-ceramics or covered with composite veneer material; cementation of inlays, onlays, crowns, and bridges made from composite or ceramics has provided these suitable for conventional cementing; cementation of posts and screws; they are suitable as luting cement for use on orthodontic bands.

\section{Material and method}

For this study, we conducted assessments using an operator microscope (Zeiss Germany, with magnification $\mathrm{x} 10$ and $\mathrm{x} 14$ ), investigating the orthodontic ring-cement interface, considered in the direction of the occlusal surface, on 16 teeth, divided into 4 groups (each 4 teeth for each orthodontic cement type), at an interval of 7 days after setting the disjunctor or orthodontic rings in the mouth of the patient, exposing the interface to the methylene blue dye.

\section{Results and discussion}

We accomplished a comparison of the occlusal microleakage scores on cement-ring interface between the four studied cementing materials: Adhesor (Spofa Dental), Ketac Cem (3M ESPE), Fuji Ortho (GC), Transbond Plus (3M Unitek).

Dye impregnation methodology is commonly used to highlight products microleakage on the cement-metal interface.

For the first group of molars we used Adhesor (Spofa Dental) cement for cementing of the orthodontic rings.

Significant cracks (A, B, C) were recorded, radially arranged and virtual spaces extended to the interface between cement and metal enamel, respectively (Table I and Figure 1). 
Table I. - The incidence of the facial and oral cracks for cementing orthodontic rings using Adhesor cement (Spofa Dental)

\begin{tabular}{|c|c|c|}
\hline Tooth & Facial surface & Oral surface \\
\hline T1 & 11 & 10 \\
\hline T2 & 15 & 13 \\
\hline T3 & 14 & 14 \\
\hline T4 & 13 & 14 \\
\hline
\end{tabular}
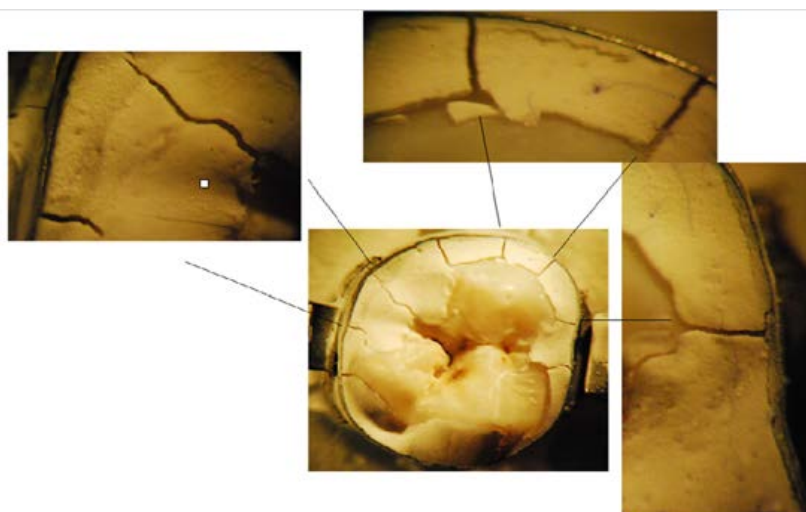

Figure 1. Optical microscopy image (magnification $x 10$ ) and detailed images $A, B, C$ (magnification x14) for cementing orthodontic rings using Adhesor cement (Spofa Dental)

On the second group of molars, we used Ketac Cem( 3M ESPE) cement for adhesive cementing of the orthodontic rings.

Appearance of small uneven gaps, parallel oriented $(\mathrm{B}, \mathrm{C}, \mathrm{D})$, alternating with extended virtual space (the central image) (Table II and Figure 2).

Table II. The incidence of the facial and oral cracks for orthodontic rings cementation with Ketac Cem (3M ESPE)

\begin{tabular}{|c|c|c|}
\hline Tooth & Facial surface & Oral surface \\
\hline T1 & 12 & 8 \\
\hline T2 & 14 & 7 \\
\hline T3 & 16 & 9 \\
\hline T4 & 13 & 12 \\
\hline
\end{tabular}

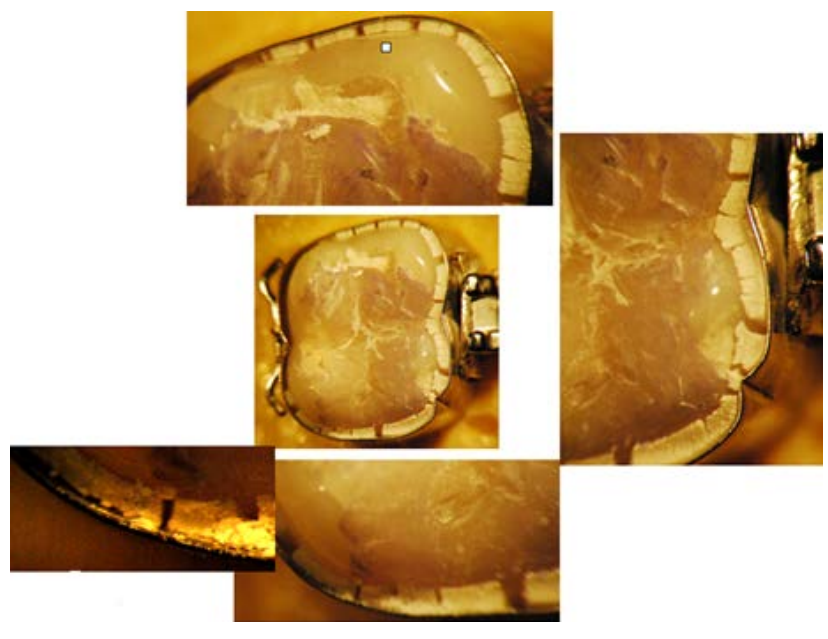

Figure 2. Optical microscopy image (magnification x10) and detail images $A, B, C, D$ (magnification x14) for adhesive cementing the orthodontic rings with Ketac

Cem (3M ESPE) cement

For the third group of molars, we used Ortho Fuji( GC) cement for adhesive cementing of the orthodontic rings.

Rare lacunar zones were recorded $(\mathrm{A}, \mathrm{B}, \mathrm{C})$ which were arranged along fine cracks (A) (Table III and Figure 3).

Table III. The incidence of the facial and oral fissures for cementation of orthodontic rings with Ortho Fuji (GC) cement

\begin{tabular}{|c|c|c|}
\hline Tooth & Facial surface & Oral surface \\
\hline T1 & 7 & 4 \\
\hline T2 & 9 & 3 \\
\hline T3 & 6 & 5 \\
\hline T4 & 5 & 6 \\
\hline
\end{tabular}



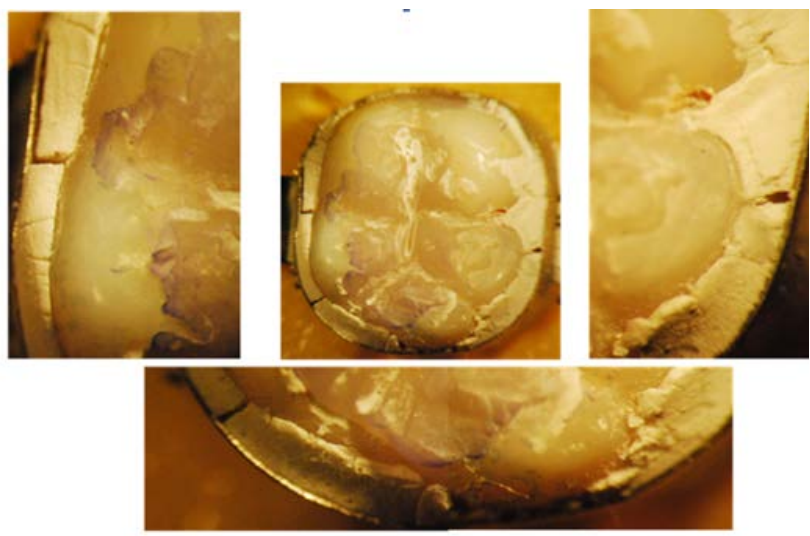

Figure 3. Optical microscopy image (magnification $x 10)$ and detail images $A, B, C$ (magnification x14) for the cementing orthodontic rings with Fuji Ortho (GC) cement

For the fourth group of molars, we used Transbond Plus( 3M Unitek) cement for adhesive cementing of the orthodontic rings.

The appearance of the fixing material of the ring expressed few structure changes. However, rare fine cracks with virtual areas limited in length and number have been observed (Table IV and Figure 4).

Table IV. The incidence of the facial and oral fissures for cementation of orthodontic rings with Transbond Plus( $3 M$ Unitek) cement

\begin{tabular}{|c|c|c|}
\hline Tooth & Facial surface & Oral surface \\
\hline $\mathrm{T} 1$ & 4 & 2 \\
\hline $\mathrm{T} 2$ & 6 & 2 \\
\hline $\mathrm{T} 3$ & 4 & 3 \\
\hline $\mathrm{T} 4$ & 7 & 3 \\
\hline
\end{tabular}
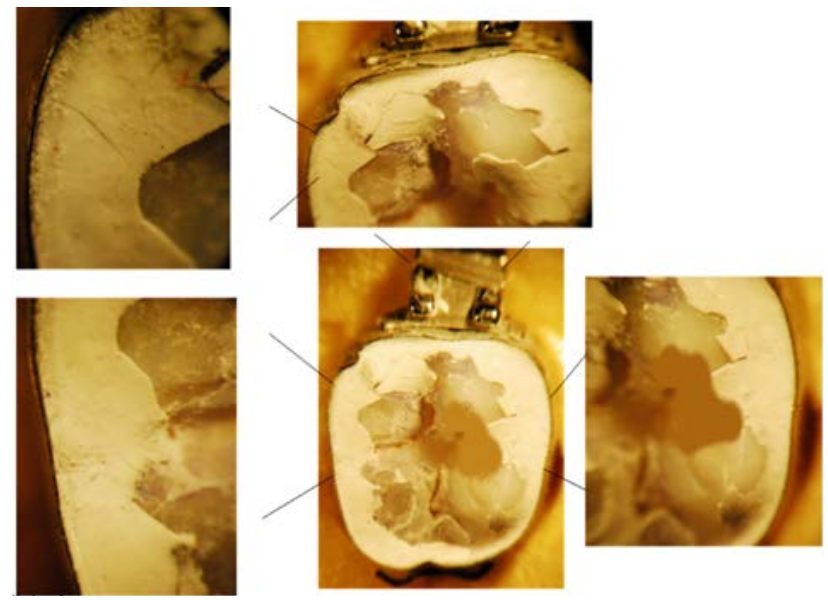

Figure 4. Optical microscopy image (magnification $x 10$ ) and detail images $A, B, C, D$ (magnification x14) for cementing the orthodontic rings with Transbond Plus(3M Unitek) cement

\section{Conclusions}

Adhesor (Spofa Dental) shows poor results in terms of cementing and pulp protection than the other orthodontic tested cements.

Transbond Plus( $3 \mathrm{M}$ Unitek) is the preferred adhesive material for cementing the orthodontic rings, compared to conventional glass ionomer cements, due to the protection it offers against microleakage which has been highlighted at the interface cementorthodontic ring.

This however, entails a lower potential for microbial penetration while minimizing the possibility of loosening the orthodontic rings.

Nevertheless, the microleakage score recorded at the vestibular interface compared with the lingual one is similar, and cementing the orthodontic rings with glass inomer cements like Ketac Cem (3M ESPE) or Fuji Ortho (GC) presents a higher microleakage score. 


\section{References}

1. Millett D.T., McCabe J.F., Bennett T.G., Carter N.E. \& Gordon P.H. (1995). The effect of sandblasting on the retention of first molar orthodontic bands cemented with glass ionomer cement. Br J Orthod. 22,161-9.

2. Cacciafesta V., Sfondrini M.F., Tagliani P. \& Klersy C. (2007). In-vitro fluoride release rates from 9 orthodontic bonding adhesives. American Journal of Orthodontics and Dentofacial Orthopedics. 132, 656-62.

3. Foley T., Aggarwal M. \& Hatibovic-Kofman S. (2002). A comparison of in vitro enamel demineralization potential of 3 orthodontic cements. Am J Orthod Dentofacial Orthop. 121, 526-30.

4. Crenor S.L., Saunders W.P., Carruthers L.M.C, Strang R. \& Foye R.H. (1995). Effect of extrinsic fluoride concentration on the uptake and release of fluoride from glass ionomer cerments. Caries Res. 29,424-6.

5. Gaintantzopoulou M.D., Willis G.P. \& Kafrawy A.H. (1994). Pulp reactions to light-cured glass ionomer cements. Am J Dent. 7, 39-42.

6. McNeill C.J., Wiltshire W.A., Dawes C. \& Lavelle C.L. (2001). Fluoride release from new ligth-cured orthodontic bonding agents. Am J Orthod Dentofacial Orthop. 120,392-7.
7. De Munck J., van Meerbeek B., Yoshida Y., Inoue S., Suzuki K. \& Lambrechts P. (2004). Four-year water degradation of a resin-modified glass-ionomer adhesive bonded to dentin. Eur $J$ Oral Sci. 112, 73-83.

8. Dubroc G.C., Mayo J.A. \& Rankine C.A. (1994). Reduction of caries and of demineralization around orthodontic brackets: effect of a fluoridereleasing resin in the rat model. Am J Orthod Dentofacial Orthop. 106,583-7.

9. El Mallakh B.F. \& Sarkar N.K. (1990). Fluoride release from glass-ionomer cements in deionized water and artificial saliva. Dent Mater. 6, $118-22$

10. Yap A., Stokes A.N. \& Pearson G.J. (1996). An in vitro microleakage study of a new multipurpose dental adhesive system. J Oral Rehabil. 23, 302-8.

11. Millett D.T., Cattanach D., McFadzean R., Pattison J. \& McColl J. (1999). Laboratory evaluation of a compomer and a resin-modified glass ionomer cement for orthodontic bonding. Angle Orthod. 69,58-63

12. Forsten L. (1991). Fluoride release and uptake by glass ionomers. Scand J Dent Res. 99, 241-45.

13. Geurtsen W. (1998). Substances released from dental resin composites and glass ionomer cements. Eur J Oral Sci. 106, 687-95.

14. Fox N.A. (1990). Fluoride release from orthodontic bonding materials. An in vitro study. Br. J Orthod. 17, 293-8. 